УДК 611.01

\title{
ПОЛОВОЙ ДИМОРФИЗМ МОРФОЛОГИЧЕСКИХ ПОКАЗАТЕЛЕЙ У ЖЕНЩИН, ЗАНИМАЮЩИХСЯ РАЗЛИЧНЫМИ ВИДАМИ СПОРТА
}

Ткачук Марина Германовна д.б.н., профессор, зав. каф. анатомии Дюсенова Алтын Акмырзаевна к.м.н., доцент, доцент каф. анатомии Национальный государственный университет физической культуры, спорта и здоровья имени П.Ф. Лесгафта, Санкт-Петербург

Аннотация: В работе представлены данные об особенностях телосложения спортсменок, занимающихся художественной гимнастикой, спортивной аэробикой, фигурным катанием (традиционно женскими видами спорта), боксом, борьбой, фехтованием (традиционно мужскими видами спорта), занимающиеся лыжными гонками и плаванием (гендерно нейтральными видами спорта). Программа исследования включала в себя антропометрию, определение компонентного состава тела и соматометрию по методу Хит-Картера. Контингент испытуемых - 248 спортсменки в возрасте 1825 лет, имеющих спортивную квалификации от 1 взрослого разряда до мастера спорта международного класса. Контрольную группу составили 42 женщины того же возраста, не занимающиеся спортом.

Ключевые слова: спортсменки, антропометрия, соматотип, половой диморфизм, маскулинизация.

\section{SEXUAL DIMORPHISM OF MORPHOLOGICAL NDICATORS IN WOMEN ENGAGED IN VARIOUS SPORTS}

\section{Tkachuk Marina Hermanovna Dusenova Altyn Akmyrzayevna}

\begin{abstract}
The work presents data on the physique of athletes engaged in rhythmic gymnastics, sports aerobics, figure skating (traditionally women's sports), boxing, wrestling, fencing (traditionally men's sports), engaged in skiing and swimming (gender-neutral sports). The study program included anthropometry, body
\end{abstract}


component composition determination and Hit-Carter somatometry. The group of subjects - 248 athletes aged 18-25 years, having sports qualifications from I adult to master of sports of international class. The control group consisted of 42 women of the same age, not requested.

Key words: athletes, anthropometry, somatotype, sexual dimorphism, masculinization.

Еще в начале 20 века венский (австрийский) натурфилософ О. Вейнингер в принципиальном исследовании мужского и женского начал «Пол и характер» указал на очевидность полового многообразия, несостоятельность классификации человечества на мужчин и женщин и, вместе с тем, на отсутствие попыток исследования «спорных пунктов с точки зрения индивидуальной созданности каждого из них» при бесчисленности переходных степеней между ними [1]. Принимая андрогинию, понятие, введенное американским психологом С. Бем [2], как проявление у человека, конкретного индивидуума, традиционно мужских и традиционно женских качеств, при разнообразии сочетаний тех и других, гармоничном или неэквивалентном, руководствуясь фактами, обоснованными научными исследованиями, известные психологи, сексологи и психиатры [3; 4;], подтвердили заключение О. Вейнингера.

Вместе с тем, половой диморфизм как фенотипические различия между представителями мужского и женского пола имеет не только анатомические проявления, но и морфофункциональные, психологические, поведенческие, касаясь не только биологического, но и социального статуса, форм общественной деятельности в широком многообразии ее проявлений.

Развивая эволюционную теорию пола, В.А. Геодакян в основу дифференциации полов положил тенденцию сохранения и закрепления выгодных признаков для наследования их [5]. С одной стороны, и необходимость разнообразия потомков, их изменений для придания эволюции направления, обеспечивающего приспособление к условиям среды обитания. Противоположность тенденций находит отражение в половом диморфизме и различии ролей мужчин и женщин в эволюционном процессе, при том, что разнообразие признаков в мужской и женской популяциях - дисперсия полов имеет характерные величины для каждой. Этот разброс, отклонения от некоей средней нормы пола - множество соматических особенностей, таких как особенности телосложения, строения и функций внутренних органов, 
выраженность вторичных половых признаков, психологических черт и других качеств предусматривается понятием полового диморфизма. Половой диморфизм, соотношение полов определяются как эволюцией, так и условиями воздействий среды.

Интегральной подход к половой дифференциации человеческих особей предполагает оценку таких полозависимых характеристик (признаков) как анатомическое строение половых органов в качестве репродуктивной составляющей, пропорций тела, степени выраженности и распределения жира и скелетных мышц как общесоматической составляющей, и полового самосознания индивидуума представителем определенного пола с наличием стереотипа полового поведения, свойственного ему как составляющей поведенческой и социальной.

Однонаправленность всех компонентов служит общепринятой нормой определения половой принадлежности, значимой для формирования пола ребенка в постнатальном онтогенезе. Вместе с тем, пол, не будучи лишь данностью, испытывает влияния природы и социума, что требует при определении принадлежности к нему учета сложных механизмов, лежащих в системе иерархических отношений в широком диапазоне от наследственной программы до выбора партнера.

Если под генетическим полом понимают находящиеся в половых хромосомах дифференцированные по полу гены (пол формирует экспрессия 18 19-го гена половых хромосом), то полное развертывание наследственной программы определяет, как дифференцирование гонад - проявление гонадного, или истинного пола, так и гормонозависимых вторичных признаков пола гормональный пол. Идентификация гонадного пола предусматривает оценку анатомического и гистологического строения половых желез, что служит основным показателем половой принадлежности. Гормональным полом, по мнению И.С. Кона [6], является способность половых желез осуществлять секрецию специфических половых гормонов, при доминирующей роли андрогенов в детерминации пола на стадии его формирования. Наличие или отсутствие андрогенов у индивидуума в пренатальном его развитии определяет проявление полозависимых признаков: внутренних (типа полового тракта) и внешних гениталий, молочных желез, особенностей секреции гонадотропных гормонов - циклический или ациклический их характер, характер полового поведения и парасексуальных реакций, особенности функциональных систем организма. 
Различие социальных ролей, видов и форм общественной деятельности, поведения и психологических характеристик людей определяют, наряду с биологическим, гендерный пол, то есть складывающийся, формирующийся в социокультурной среде социальный или психологический пол [7]. Не смешивая понятий пол и гендер, последний предполагает возможность влияния факторов среды на формирование личностных особенностей, соответствующих стереотипным моделям представителей полов - маскулинности как мужской и фемининности - женской вариации. Социализация мужчин в большей степени предусматривает физическую деятельность, занятия спортом, способствующие формированию, наряду с силой, таких личностных качеств как целеустремленность и настойчивость, при высокой значимости мотивов социального и реализации энергии в действии, достижения победы, лидерства и успешности. Приоритетом для женщин в физической деятельности является ее оздоровительный и развлекательный характер, осуществление ее в команде, обретение мастерства без доминирующей установки на победу [8]. Агрессивный физический контакт ряда видов спортивной деятельности, предпочтение которым отдают мужчины, составляет часть мужского имиджа. Типичными чертами тех, что предпочитают женщины, являются грациозность, красота, гармоничность, элегантность движений [9].

Биологическая, базирующаяся на морфофункциональных характеристиках, и психологическая, связанная с личностными и поведенческими особенностями, стороны природы различий объясняют их сущность.

Индивидуальными характеристиками фенотипических проявлений генетической конституции служат генетические маркеры. Маркеры устойчивые признаки организма, связанные с генотипом, и абсолютными среди них являются те, что сохраняются неизменными на протяжении всей жизни человека (дерматоглифические, одонтоглифические показатели, группа крови, доминирование полушария головного мозга), а условными - те, подвержены изменениям под воздействием внешних средовых факторов, включая социальные - тип темперамента, характерологические особенности [10].

Генетическое маркирование основывается на тесном сцеплении находящихся в одной хромосоме совместно наследуемых генов: гена, кодирующего проявление определенного свойства с геном, отвечающим за формирование легко обнаруживаемого, доступного наблюдению фенотипически проявляемого признака. Обнаружение признака-маркера 
позволяет судить о наличии или отсутствии предрасположенности развития морфологического признака или функционального свойства - двигательной способности человека.

Среди генетических маркеров различают серологические (группа крови), морфологические и одонтоглифические, иридологические, функциональные, хромосомные, гормональные. Оценка соматотипа женщин с диморфических позиций выделяет его фемининный и маскулинный варианты. Фемининный вариант отличает женский тип телосложения, отвечающий детородной функции, с относительно узкими плечами, широким тазом, малой длиной ног и средним ростом 158 см при доли мышечного компонента в составе тела 32\%, а жирового - 28\%. Женщинам маскулинного типа свойственны широкие плечи и узкий таз, длинные ноги при среднем росте 170 см с относительно низким 12\% содержанием жирового компонента и высоким мышечного - 50\% [11]. Перечисленные морфологические признаки маскулинизации спортсменок связаны с дисбалансом половых гормонов, проявлением которого является гипоэстрогения [12].

Установленная в настоящее время принадлежность жировой ткани к секреторным органам связана с синтезом ею гормонов - эстрогенов, определяющих фемининные качества. В составе тела женщины с нормальным овариально-менструальным циклом на долю жирового компонента приходится не менее $22 \%$ [13].

Степень выраженности признаков полового диморфизма различна на протяжении периодов онтогенеза, так в пубертатном периоде, до наступления полового созревания между силовыми показателями представителей обоих полов существенных отличий не наблюдается, в то время как в период от 13-15 до 30 лет при возрастающей активности половых гормонов, их различия становятся отчетливее [14]. Влиянием половых гормонов обосновывают и менее значительный эффект силовой тренировки женщин-спортсменок, обладающих относительно меньшей мышечной массой в сравнении с мужчинами, что определяет и относительно низкий уровень анаэробных процессов, поскольку характер энергетических процессов определяется содержанием андрогенов в организме. Поступление глюкозы из депонирующих ее органов, распад жиров, выделение катехоламинов интенсивнее происходят в организме мужчины, обеспечивая более быструю мобилизацию, реагирование, их приспособление к физическим нагрузкам в сравнении с женщинами, на чем основывается предположение о сходстве энергообеспечения мышечной 
активности женщин-спортсменок, особенно занятых в маскулинных видах (борьбе, боксе, тяжелой атлетике, фехтовании и других), с таковым у мужчин, способствуя развитию у женщин качеств силы, скорости движений, выносливости. При том, что закономерная тенденция преобладающего влияния внешней среды на развитие абсолютной мышечной силы, а наследственности на развитие силы относительной, установлена для представителей обоих полов, среда как образ жизни, физический труд, физическая культура, спорт в большей степени влияет на развитие абсолютной мышечной силы мужчин. Подчиненные генетическому контролю скоростные способности формируются у женщин медленнее, чем у мужчин.

Воздействие интенсивных физических нагрузок на развивающийся женский организм в периоды, предшествующие зрелости - детский, подростковый, юношеский, приводят на фоне генетической предрасположенности к формированию маскулинного типа женщины. Частота встречаемости среди спортсменок высокой квалификации тех, что обладают мужским соматотипом составляет 44\% среди занимающихся плаванием, 67$71 \%$ у футболисток и лыжниц, 70-90\% среди легкоатлеток и 98\% у представительниц спортивной гимнастики. Абсолютному большинству женщин, не занимающимся спортом, свойственен фемининный тип телосложения, частота встречаемости мужского соматотипа среди них низка [15].

Ряд функциональных показателей представительниц спортивной элиты, в частности уровень потребления кислорода, близки или превосходят таковые у слабо тренированных мужчин. У женщин, не занимающихся спортом, показатель потребления кислорода на 20-30\% ниже, чем у мужчин.

Корреляционные связи компонентов конституции обнаруживают существенные диморфические различия. Так, у обследованных мужчин установлены прямые корреляционные связи показателей длины тела, массы тела, обхвата груди, обхвата плеча, ширины плеч, ширины таза, толщины кожно-жировых складок плеча, живота, ширины запястья с показателями распознавания образов и эффективности одновременных и последовательных интеллектуальных действий [16]. Оценка тех же показателей обследованных им женщин выявила обратную и более низкую корреляцию между ними. Прямая корреляционная связь соматометрических и психометрических показателей, возростающих у мужчин с улучшением физического состояния в благополучных условиях среды, по мнению автора исследования, имеет социальную обусловленность. 
Очевидная морфологическая маскулинизация спортсменок при спорности причин и механизмов этой трансформации определяет сложность и актуальность проблемы, что определило направление и задачи комплексного морфологического исследования представительниц различных спортивных специализаций, проведенного в Национальном государственном университете физической культуры, спорта и здоровья им. П.Ф. Лесгафта, Санкт-Петербург. Среди принявших в нем участие 248 студенток-спортсменок 18-25 лет со спортивным стажем не менее 7 лет, обладающих спортивной квалификацией от 1-го взрослого разряда до мастера спорта международного класс, выделены три группы, в первую из которых вошли те, кто специализируется в маскулинных, традиционно мужских видах спорта - боксе, борьбе и фехтовании. Вторую группу составили представительницы фемининных, традиционно женских спортивных специализаций - художественной гимнастики, спортивной аэробики и фигурного катания, а третью - женщины, занимающиеся лыжными гонками и плаванием - гендерно нейтральных видов спорта, в которых заняты представители обоих полов. В контрольную группу вошли 42 женщины аналогичного возраста, не занимающиеся спортом.

Используя антропометрические методы исследования для оценки морфологических показателей, у испытуемых проводили измерение массы тела, высоту положения стандартных антропометрических точек, парциальные, поперечные и обхватные размеры тела и конечностей, толщину кожно-жировых складок.

Определение соматотипа участниц исследуемых групп проводилось с использованием схемы Хит-Картера [17], определяющей доли (в баллах) трех компонентов в составе тела, оценка соотношения которых характеризовала эндоморфию как тип телосложения со значительным развитием внутренних органов и избыточным жироотложением, мезоморфию - при хорошо развитых мускулатуре и скелете, а эктоморфию как тип, отличающийся хрупкостью, вытянутостью тела.

Характер морфофункциональных адаптационных изменений организма спортсменок к физическим нагрузкам связан с видом спортивной специализации, имеет особенности для каждой из них. Так, согласно результатам наших исследований спортсменок, занимающихся борьбой, боксом, фехтованием при сходстве их роста со сверстницами, не занимающимися спортом, отличает достоверно меньшая длина конечностей, как верхних, так и нижних, что обеспечивает им большую устойчивость в 
ортостатическом положении из-за относительно низкого положения общего центра тяжести их тела. Показатели окружности грудной клетки, обхватных измерений плеча и предплечья у всех представительниц маскулинных спортивных специализаций оказались достоверно большими таких показателей у участниц контрольной группы, причиной чего является высокая степень развития мышц этих областей тела и конечностей у спортсменок. При этом наибольшая окружность грудной клетки обнаружена у специализирующихся в видах борьбы: она составила $88,9 \pm 1,52 \mathrm{cm;} \mathrm{наибольшие} \mathrm{по} \mathrm{величине} \mathrm{окружности}$ бедра $(56,2 \pm 0,42 \mathrm{~cm})$ и голени $(36,0 \pm 0,30$ см) отмечены у фехтовальщиц.

Спортсменки маскулинных видов спорта (первой группы участниц исследования) продемонстрировали более высокие значения ширины плеч, большие поперечные размеры дистального отдела плеча и предплечья в сравнении с контрольной группой участниц при сходстве параметров таза у обеих групп.

В составе тела представительниц первой группы, занимающихся борьбой, боксом, фехтованием, отмечены высокие показатели мышечного компонента, наибольшие - у фехтовальщиц $(45,7 \pm 0,16 \%)$ с превышением на 7,5\% этого показателя у участниц контрольной группы, в то время как у занимающихся борьбой выявлена высокая доля жирового компонента, близкая к содержанию его в составе тела не занимающихся спортом женщин (контрольной группы).

Меньшее содержание жирового компонента тела среди участниц первой группы испытуемых обнаружено у спортсменок, занимающихся боксом $(22,0 \pm 0,70 \%)$ с соответственно меньшей, в сравнении с остальными спортсменками группы, и толщиной кожно-жировых складок: у девушекбоксеров средняя толщина их составила $12,6 \pm 0,16$ мм, у специализирующихся в

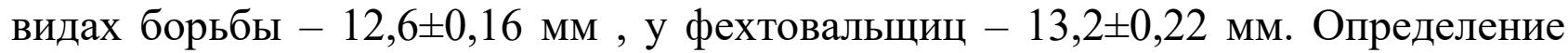
относительной массы костного компонента у спортсменок маскулинных видов спорта и участниц, не занимающихся спортом различий между ними не продемонстрировало.

Мезоморфный тип телосложения у представительниц маскулинных видов спорта (первой группы участниц исследования) оказался преобладающим с наибольшими показателями мезоморфии $(5,0 \pm 0,49$ баллов) и эктоморфии $(2,9 \pm 0,54$ балла) у фехтовальщиц. Наиболее высоким показателем эндоморфии в первой группе участниц отмечены женщины-борцы $(3,8 \pm 0,54$ балла).

Морфометрические исследования участниц второй группы представительниц фемининных видов спорта обнаружили у них более высокий 
рост и длину верхних и нижних конечностей, чем у не занимающихся спортом ровесниц. Преобладающий показатель роста - 170,0 11,51 см отмечен у гимнасток, что на 6 см превысило это показатель спортсменок-аэробисток и на 4 см рост фигуристок. Длина верхних конечностей $(75,2 \pm 0,72$ см) и нижних конечностей $(92,6 \pm 1,12$ см) гимнасток оказалась наибольшей в исследуемой группе, характерным для фигуристок явились высокие значения длины корпуса $(75,0 \pm 1,3$ см), голени $(39,4 \pm 2,11$ см) и кисти $(19,0 \pm 0,4$ см) при наименьшей длине нижних конечностей у них среди всех участниц группы. Относительно небольшая величина длины нижних конечностей при большой длине корпуса обеспечивает представительницам этого вида спорта устойчивость на ограниченной площади опоры скользкой поверхности по завершении выполнения ими сложных прыжков с большим числом оборотов.

Сравнение обхватных параметров представительниц фемининных и маскулинных спортивных специализаций выявило преобладание их $\mathrm{y}$ последних, что несомненно отражает черты морфологических модельных характеристик видов спорта, формирующихся спецификой тренировочного процесса и требованиями спортивного отбора. Соответствие индивидуальных соматотипических характеристик модельной характеристике вида спорта один из факторов высокой результативности в достижениях это вида спорта. Самыми низкими значениями окружности плеча, предплечья, бедра отмечены гимнастки.

Показатель ширины плеч всех спортсменок второй группы превысил таковой у участниц контрольной группы исследования. Его значение у гимнасток составило 37,6 $\pm 0,79$ см, у представительниц спортивной аэробики $37,8 \pm 1,52 \mathrm{~cm}$, у фигуристок - 37,6 $\pm 0,43$ см, а не занимающихся спортом ровесниц - 35,3 $\pm 0,44$ см. В то же время, отличия поперечных размеров дистальных отделов верхних и нижних конечностей спортсменок этой группы от подобных им у женщин контрольной группы оказались несущественными: поперечные размеры дистального отдела предплечья гимнасток составили

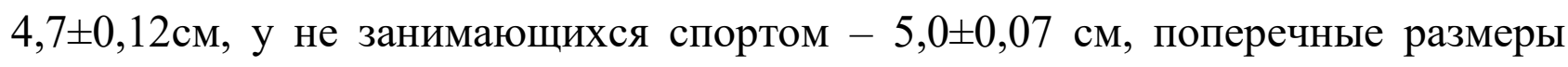
дистального отдела голени - 6,1 $\pm 0,12$ см и 6,5 $\pm 0,15$ см соответственно.

Оценка поперечных размеров таза женщин-спортсменок фемининных специализаций обнаружила достоверно меньшую величину исследуемых параметров у занимающихся художественной гимнастикой и превышение их значений у фигуристок в сравнении с участницами, составившими контрольную группу. Достоверных различий поперечных размеров таза 
представительниц спортивной аэробики и женщин, не занимающихся спортом, обнаружить не удалось.

В компонентном составе тела представительниц второй исследуемой группы - гимнасток, фигуристок отмечены высокие показатели мышечного компонента при низких жирового в сравнении с их долями у женщин контрольной группы. Исследования Э.Г. Мартиросов и соавт. [18] свидетельствуют об увеличении мышечного компонента в составе тела и росте скоростно-силовых качеств спортсменок на фоне снижения их жировой массы.

Наибольшие показатель жирового компонента тела $(21,4 \pm 0,18 \%)$ и толщины кожно-жировых складок $(12,2 \pm 0,12$ мм $)$ продемонстрировали фигуристки. Толщина кожно-жировых складок занимающихся спортивной аэробикой женщин и гимнасток составила $11,6 \pm 0,06$ мм и $11,3 \pm 0,08$ мм соответственно. Среди женщин, не занимающихся спортом показатель массы жировой ткани в составе тела колебался в пределах $(27,1 \pm 1,33 \%$ при толщине

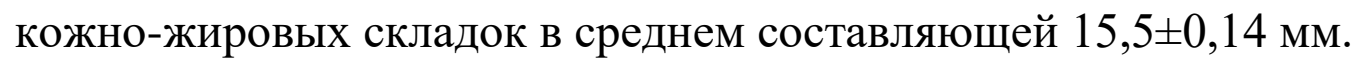

Результаты соматотипирования спортсменок фемининных специализаций с использованием схемы Хит-Картера обнаружили преобладание мезоморфного типа телосложения в этой группе с самым высоким показателем мезоморфности $(4,8 \pm 0,5$ балла) у участниц, занимающихся спортивной аэробикой (табл. 1). Наивысший показатель эктоморфности, составляющий $4,2 \pm 0,38$ балла отмечен у гимнасток, в то время как эндоморфия проявила себя в большей степени у фигуристок $(3,4 \pm 0,54$ балла) и в меньшей степени у гимнасток $(2,5 \pm 0,33$ балла).

Таблица 1

Компонентный состав массы тела в различных группах $\left(\overline{\mathrm{x}} \pm \mathrm{S}_{\overline{\mathrm{x}}}\right)$

\begin{tabular}{|l|c|c|c|c|}
\hline \multirow{2}{*}{ Компоненты массы тела } & \multicolumn{4}{|c|}{ Группы } \\
\cline { 2 - 5 } & $\begin{array}{c}\text { Худ. гимн. } \\
(\mathrm{n}=31)\end{array}$ & $\begin{array}{c}\text { Аэробика } \\
(\mathrm{n}=30)\end{array}$ & $\begin{array}{c}\text { Фиг. катание } \\
(\mathrm{n}=29)\end{array}$ & $\begin{array}{c}\text { Контроль } \\
(\mathrm{n}=42)\end{array}$ \\
\hline Жировой компонент (\%) & $19,9 \pm 0,18^{*}$ & $20,5 \pm 0,16^{*}$ & $21,4 \pm 0,18^{*}$ & $27,3 \pm 1,33$ \\
\hline Мышечный компонент (\%) & $42,0 \pm 0,18^{*}$ & $43,7 \pm 0,18^{*}$ & $42,8 \pm 1,22^{*}$ & $38,2 \pm 1,17$ \\
\hline Костный компонент (\%) & $16,5 \pm 0,22$ & $16,7 \pm 0,34$ & $17,6 \pm 0,44^{*}$ & $16,0 \pm 0,5$ \\
\hline
\end{tabular}

Примечание: $\mathrm{n}$ - объем выборки; * - различия статистически достоверны, по сравнению с контрольной группой, $\mathrm{p}<0,05$ 
В группе спортсменок нейтральных, избираемых как женщинами, так и мужчинами видов спорта, участницы, занимающиеся плаванием, отмечены высоким ростом, длинными корпусом и конечностями, плечами и предплечьями, характеризующими успешность проявления динамических двигательных качеств в водной среде - равновесия, плавучести, обтекаемости. У лыжниц отмечены достоверно высокие показатели длины голени.

Обхватные размеры пловчих и лыжниц превышают таковые у не занимающихся спортом женщин: наибольшая окружность грудной клетки отмечена у пловчих - 87,2 $\pm 0,91$ см, у них же наибольшей оказалась и

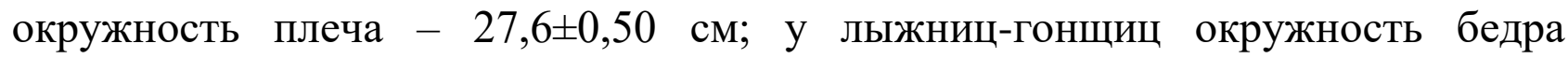
составила 56,8 $\pm 1,03$ см, что стало наибольшим значением параметра. Всех обследованных участниц группы отличало достоверно большее значение ширины плеч в сравнении контрольной группой, составившее у пловчих $41,1 \pm 1,04$ см, у лыжниц $37, \pm 1,06$ см и $35,3 \pm 0,44$ см у не занятых спортивной деятельностью. Поперечные размеры таза спортсменок нейтральной группы отличались от этих параметров участниц контрольной группы незначительно.

Высокие показатели доли мышечного компонента в составе тела пловчих $(44,0 \pm 1,56 \%)$ и лыжниц $(42,4 \pm 1,80 \%)$ наряду со значением $38,2 \pm 1,20 \%$ у не занимающихся спортом женщин контрольной группы объясняется увеличением мышечного и костного компонентов тела и снижением жирового при развитии общей выносливости.

При определении соматотипа по схеме Хит-Картера преобладающим типом телосложения представительниц нейтральных видов спорта стал мезоморфный с наиболее высоким показателем мезоморфности у пловчих, составившем в среднем 4,3 $\pm 0,24$ балла; эктоморфный и эндоморфный компоненты телосложения у пловчих и лыжниц оказались сходными (табл. 2).

Таблица 2

\section{Показатели соматотипа спортсменок $\left(\mathbf{x}+\mathrm{S}_{\mathrm{x}}\right)$}

\begin{tabular}{|l|c|c|}
\hline \multirow{2}{*}{ Компоненты телосложения } & \multicolumn{2}{|c|}{ Вид спорта } \\
\cline { 2 - 3 } & Плавание $(\mathrm{n}=36)$ & Лыжные гонки $(\mathrm{n}=32)$ \\
\hline Эндоморфия (баллы) & $3,3 \pm 0,21$ & $2,9 \pm 0,33$ \\
\hline Мезоморфия (баллы) & $4,3 \pm 0,24$ & $3,7 \pm 0,61 *$ \\
\hline Эктоморфия (баллы) & $3,5 \pm 0,28$ & $3,2 \pm 0,43$ \\
\hline
\end{tabular}

Примечание: $\mathrm{n}$ - объем выборки; * - различия статистически достоверны, $\mathrm{p}<0,05$ 
Каждый вид спорта предъявляет специфические требования к телосложению спортсменов. В поиске наиболее информативных в прогностическом плане физических качеств, обеспечивающих высокие спортивные достижения, важное место отводится антропометрическим показателям. Поэтому в ходе исследования мы обратили внимание на выявление достоверно значимых антропометрических показателей, тесно связанных с «успешностью» спортсменок.

Для представительниц специализации спортивная аэробика в качестве морфологических критериев можно использовать окружность плеча и голени, длину бедра и голени. Для пловчих достоверно значимыми являются значения длины туловища, плеча и предплечья, ширина плеч и таза, а также окружности плеча, бедра и голени, для гимнасток - длина корпуса, верхних и нижних конечностей. Для спортсменок, специализирующихся в борьбе, - длина плеча и предплечья, а для женщин, занимающихся боксом, - длина плеча, предплечья и кисти. Важными характеристиками телосложения также являются пропорции тела. Для всех спортсменок достоверно значимыми оказались отношения ширины плеч (расстояние между акромионами) к ширине таза (межвертельное расстояние). Наше исследование показало, что, отношение ширины плеч к ширине таза, как наиболее яркий показатель маскулинизации, у всех спортсменок достоверно выше, чем у женщин, не занимающихся спортом. Интересно отметить, что ранее нами было выявлено, что более высокими показателями отношения ширины плеч к ширине таза отличаются элитные спортсменки от спортсменок слитного массива [19].

Одним из основных морфологических признаков является соматотип комплекс морфологических признаков (тотальных и парциальных размеров, пропорций и компонентов массы тела человека), определяющий тип телосложения в данный момент времени. Анализ результатов определения соматотипа спортсменок, проведенный нами по схеме Хит-Картера показал, что среди них 79\% составляют те, кто существенно отличаются от женщин, не занимающихся спортом, массивным скелетом и хорошо развитой мускулатурой, свидетельствующими о преобладании у них мезоморфного типа телосложения. Вместе с тем принадлежность к мезоморфному типу, как показали результаты нашего исследования, не является обязательным условием достижения спортсменками высоких результатов.

Мезоморфный тип конституции тела человека на 76-94 \% обусловлен наследственными факторами, в отличие от эктоморфного и эндоморфного 
типов. При этом, как указывают авторы, на формирование соматотипа у женщин наследственность оказывает большее воздействие, чем у мужчин.

При сравнении соматотипа всех обследованных спортсменок мы обнаружили, что для занимающихся маскулинными видами спорта характерна относительная тучность, в то время как представительницы фемининных и нейтральных видов спорта являются более худощавыми и рослыми.

\section{Список литературы}

1. Вейнингер, О. Пол и характер / О. Вейнингер. - Москва : Терра, 1992. $480 \mathrm{c}$.

2. Bem, S.L. Gender schema theory and its implications for child development Raising gender-schematic children in a gender-schtmatic society / S.L. Bem // Signs Journal of women in culture and society. - 1983. - Vol. 8, № 4. - P. 65-78.

3. Каган, В.Е. Нарушение половой идентичности / В.Е. Каган // Справочник по психологии и психиатрии детского и подросткового возраста. Санкт-Петербург : Питер, 2000. - 214 с.

4. Келли, Г. Основы современной сексологии / Г. Келли. - СанктПетербург : Питер, 2000. - 286 с.

5. Геодакян, В.А. Эволюционые хромосомы и эволюционный половой диморфизм / В.А. Геодакян // Известия Академии наук. - 2000. - № 2. - С.133148.

6. Кон, И.С. Введение в сексологию / И.С. Кон. - Москва : Медицина, 1990. - 336 с.

7. Основы гендерных исследований / под редакцией О.А. Ворониной; Московский центр гендерных исследований, Московская высшая школа социальных и экономических наук. - Москва : МВШСЭН, 2000. - 396 с.

8. Motivation for youth participant in sport and physical activity: relationship to culture, self-reported activity levels and gender / R. Weinnberg, G. Tenenbaum, A. McKenzie [et al.] // International journal of sport psychology. - 2000. - № 3. - S. $321-347$.

9. Williams, T.J. Finger length patterns indicate an influence of fetal androgenes on human sexual orientation / T.J. Williams // Nature. - 2000 - V. 404. P. 455 .

10. Сергиенко, Л.П. Основы спортивной генетики / Л.П. Сергиенко. Киев : Вища школа, 2004. - 631 с. 
11. Ткачук, М.Г. Спортивная морфология : учебник / М.Г. Ткачук, Е.А. Олейник, А.А. Дюсенова ; Национальный государственный университет физической культуры, спорта и здоровья им. П.Ф. Лесгафта, Санкт-Петербург. - Санкт-Петербург : НГУ им. П.Ф. Лесгафта, 2019. - 290 с.

12. Олейник, Е.А. Соматотипологические и экдокринологические особенности спортсменок, занимающихся борьбой и боксом / Е.А. Олейник, А.А. Дюсенова // Ученые записки университета имени П.Ф. Лесгафта. - 2013. № 2 (96). - C.116-120.

13.Калинина, Н.А. Гиперандрогенные нарушения репродуктивной системы у спортсменок / Н.А. Калинина. - Москва : ВНИИФК, 2003. - 198 с.

14. Никитюк, Б.А. Интеграция знаний в науках и человеке : (современная интергетативная антропология) / Б.А. Никитюк. - Москва : СпортАкадемПресс, 2000. $-440 \mathrm{c}$.

15. Socha, T. Female Sports : (New Knowledge - New Methods of Training) / T. Socha. - Moscow, 2002. -203 s.

16. Ильин, Е.П. Дифференциальная психофизиология мужчины и женщины / Е.П. Ильин. - Санкт-Петербург : Питер, 2002. - 544 с.

17. Хит, Б.Х. Современные методы соматотипологии / Б.Х. Хит, Дж. Е.Л. Картер // Вопросы антропологии. - 1968. - Вып. 33, Т.4. - С. 63-71.

18. Мартиросов, Э.Г. Технологии и методы определения состава тела человека / Э.Г. Мартиросов, Д.В. Николаев, С.Г. Руднев. - Москва : Наука, 2006. -137 c.

19. Ткачук, М.Г. Морфологический статус элитных спортсменок, специализирующихся в спортивной аэробике / М.Г. Ткачук // Морфология физической культуре, спорту, клинической и авиационно-космической медицине (Малаховка, 19-20 октября 2017 года). - Малаховка, 2017. C. 213-217. 